\title{
Business Intelligence and the Public Management of Destinations: The View of DMOs
}

\author{
Francisco Femenia-Serra ${ }^{(凶)}$, Aurkene Alzua-Sorzabal, \\ and Aitziber Pousa-Unanue \\ Antonio de Nebrija University, Madrid, Spain \\ ffemenia@nebrija.es
}

\begin{abstract}
Business intelligence (BI) has become a priority for destination management organizations (DMOs) that have implemented solutions to improve their decision-making and data management processes. However, not all BI initiatives have fulfilled the expectations. This paper presents an analysis of a series of interviews with DMOs in Spain, offering a snapshot of their satisfaction with $\mathrm{BI}$ and the relationship between these applications and decision making at destinations. The results suggests that one of the reasons for failure is the lack of understanding of the critical factors that define the success of BI applications. Moreover, the findings offer a novel vision of how destinations are progressively leveraging the opportunities that advanced data analysis offers, but also reveal why managers find manifold difficulties in implementing these systems. These results pose several implications for DMOs.
\end{abstract}

Keywords: Business intelligence $\cdot$ Smart destinations $\cdot$ DMOs $\cdot$ Data

\section{Introduction}

The number of digital processes carried out in tourism has expanded enormously, and the amount of data collected about visitors has equally grown $[1,2]$. This new environment requires a wide range of analytical skills and capacities in DMOs. In response to the increasing demand for customized information services, many DMOs have turned to business intelligence (BI) applications to improve their decision making. The use of the BI is widespread among most sectors [3, 4], and particularly among destinations, which employ BI today for a better understanding of demand and the changing trends in the market. However, advanced uses of BI tools are still limited. In research, there also appears to be insufficient attention given to the use of BI by destinations, its constraints and the advantages linked to their adoption. The use of intelligent systems is a key issue for destinations in their digitization process, in their transformation towards SDs $[5,6]$. Hence, the purpose of this exploratory study is to better understand how public destination managers are using intelligence for decision-making. Likewise, this study aims to identify the utility and uses of BI tools and data by DMOs. 


\section{Literature Review}

\subsection{The Concept of Business Intelligence (BI)}

BI has been defined as the technologies, applications, and processes for gathering, storing, accessing and analysing data for purposes of making better decisions [4, 7]. In addition, BI can be defined as a system comprised of both technical and organizational elements that presents historical information to its users for analysis and enables effective decision making and management support, for the overall purpose of increasing organizational performance [8]. In this paper BI is defined as a system comprising technologies, tools and software that enable an organization to gather data from numerous sources in the business and destination environment and then using technology to store, process, analyse and retrieve that data [7]. The implementation of BI systems initially demands a significant investment, but there are many benefits that organizations can take advantage of as well. Initially, BI reduces IT infrastructure costs by eliminating redundant data mining processes. BI is also seen as saving time for data providers and users through more efficient data delivery. Successful BI can represent the achievement of benefits such as improved profitability, increased efficiency, and reduced costs.

\subsection{BI and Decision-Making in Tourist Destinations}

BI systems allow to store data related to tourists' profile, experiences, places of origin, destination options and activities in which they may be interested [2, 3]. Thus, tourism organizations may plan in advanced to improve their services for tourists based on their preferences. Several authors provided clear evidence that BI systems improve the competitiveness of destinations by supporting managers understanding of tourists' behaviour and their perceptions [2, 9].

In the specific aspect of the competitiveness of destinations, it seems that, to some extent, this depends on the capacity of the territory to access enriched data and generate new content to improve its performance as a dynamic ecosystem [1, 10]. In this regard, the advances in public management of destinations through data analysis is one of the great premises of smart tourist destinations (SDs). Data-based intelligence has gained relevance in recent years thanks to the institutional drive around SDs [5]. Most of the mentioned authors, however, recognize a lack of understanding on the use of BI by destinations. Generally, these platforms are not capable of systematically integrating data from different sources or processes and, therefore, hinder the development of cross-process analyses that allow the achievement of complex and competitive data warehouses.

\section{Methods}

Based on the research objectives, four in-depth interviews were carried out with technicians and managers of Spanish tourist destinations, all engaged in the implementation of smart destination strategies, use of BI platforms, data management and 
informed decision-making. The interviewees work for DMOs of two urban and two coastal destinations and have more than 10 years of experience each in leadership roles within their organizations. The interviews took place online, with an average duration of $35 \mathrm{~min}$, being recorded and transcribed after obtaining permission from the participants. For data analysis, a thematic analysis was carried out following the guidelines established by Braun and Clarke [11]: in-depth reading of the transcripts; initial development of the main themes identified; modification, merging and elimination of topics as the analysis with the largest amount of data develops; establishment of final categories; classification of text extracts in the definitive topics.

\section{Results}

As follows, we present the main results based on the themes identified in the conducted interviews. Participants' names have been removed to preserve anonymity.

\section{Destination Idiosyncrasy and DMO's Roles}

Findings indicate that each DMO is subject to different factors that influence their approach to data management. Decision-making processes are unique in each destination and so are the employed data analysis systems. In this regard, the budget and volume of tourism business at the local scale seem to condition the relationship between businesses and DMOs when it comes to data provision. Moreover, data collection is also marked by the size of the floating population, which implies a higher degree of complexity in gathering and analyzing data. Destinations acknowledge that visitors can bias the conclusions obtained from residents' data and vice versa, which is a challenge for them and makes choosing the right BI platform even more important.

\section{Data Usefulness}

Participants argue that destinations' use of BI is driven by their main objectives when employing data: destination promotion and positioning, market segmentation, events organization or tracking competitors. A lack of long-term planning strategy when using data is detected, as short-term marketing strategies seem to prevail in their projects. Mobile and social media data have become more important to conduct such projects.

"Social media and behavioral data are helping us a lot in strategic decisions [...] We used to struggle a lot to get those data through face-to-face surveys." (P2)

Data come from traditional sources (such as statistical institutes), but increasingly from accommodation platforms, metasearch engines, social media, etc. Expenditure continues to be the most complicated data to obtain. To overcome these difficulties, some destinations collaborate with scientific experts, who can help them in analyzing certain types of complex data. Therefore, destination managers feel that BI systems need to empower them and help them understand complex data in a simple way. Also, the real usefulness of some data is called into question and data overuse is noted by one of the interviewees as a problem:

"There are a lot of data, but I don't need them all. The key is to be selective and ask yourself:

why do I need this data? Because having too many data can be annoying." (P4) 


\section{Platforms and Types of Data}

A critical issue when developing a BI platform is whether the destination develops it with its own means or prefers to hire the services of a company. As participants state, managing this type of platform requires many resources but eliminates the dependency on external providers. The purchase of data from IT companies or banks also creates an important dilemma for DMOs due to their high price and their limited budgets.

Some destinations are working on the development of their own data platform by using Microsoft Power BIC in which destinations integrate most of the data coming from different sources. This tool is specially valued for its simplicity and visual nature. Platforms are fed with data coming from traditional sources that are now digitalized, such as surveys conducted at tourism offices. Similarly, some destinations are implementing sensors that also feed their data platforms with new parameters. However, the satisfaction with this service is low among those who are already using it. Technical difficulties, additional costs and lack of usefulness are reported by some, who also acknowledge the slowness of public administrations in adapting to new requirements.

"These companies are selling smoke. They don't even know what they're selling. They sell you these nice platforms and all the data they get, but the reality is different." (P3)

Some participants argue that IT and telecommunication companies sell "packages" of data and prearranged platforms that do not match each destination needs. The adaptation of BI platforms to their needs is seen as critical by DMOs, as each actor within the destination has different data requirements. Regarding the design of BI platforms, DMOs seem to need new types of data visualization options (graphics), the integration of Geographical Information Systems (GIS) and the updating of all data regardless of the employed platform.

\section{Resources and Future Tendencies}

One of the most important issues identified is the very limited human, technical and financial resources that DMO have, and which hinder their capacity to leverage data. Having a data expert in their team, who would be in charge of developing data-based reports, creating graphics, and keeping them, is seen by DMOs as a requirement today.

"We just try to stay afloat among all those data, trying to understand and keep focused, but we don't have a big team. There's no one who only works in data analysis." (P1)

Additionally, the resources to implement BI platforms and new infrastructure to capture data depend on budgets that are subject to public tenders and calls by the national and regional governments. This means destinations see their projects slowed down because of bureaucracy and monitoring of projects. Similarly, the lack of coordination between administrations seems to be a problem for an optimal management of data.

In terms of future needs, the pandemic caused by COVID-19 has increased the need to have updated information and new variables in data platforms, such as capacity and access to public areas, including beaches and parks. Having more updated data can help destinations predict the behavior of demand in the short term, which is more important than ever in the pandemic context. Some data, such as real-time number of visitors in attractions and access to natural areas will be needed also after the pandemic according 
to the opinion of participants. Finally, the interviewees recognize that the future will be marked by new challenges, including climate change. These challenges require having more detailed data on the impacts of tourism and a close monitoring of indicators.

\section{Conclusions}

This exploratory work has examined how public destination managers use BI platforms and data analysis for their decision making in a changing context. The results show that destinations have specific needs, limited resources and capacities and that BI needs to adapt to these. One of the causes of failure in BI applications is the lack of quality data, which not only refers to data from appropriate and reliable sources, but also involves the extent these data are adapted to the needs of the destination. Flexibility - in terms of data sets, user access and data visualization - is therefore considered a needed attribute of BI platforms, as pointed by previous research [12]. The simplicity of the systems is also crucial to guarantee the real use among the destination managers. The success of BI tools is proportional to the benefits that tourism organizations obtain, but success can also be subjectively measured by their users [13]. It is recalled the need of cohesion between the strategies of the organization, the target user of the tools and their use of BI applications [14]. Still, this study has shown that destinations are making limited use of the strategic opportunities provided by BI, which may be related to the shortage of human, technical and financial resources. Overall, the obtained results contribute to the literature on BI applied to destinations management by, but also to the use of big data by DMOs and the barriers existing in this area. Future research is needed to understand how different BI tools can be employed to address variegated destination management problems. The conducted study presents limitations such as representativeness that need to be address with further research.

\section{References}

1. Buhalis D (2006) The impact of information technology on tourism competition. In: Papatheodorou A (ed) Corporate rivalry and market power: competition issues in the tourism industry, pp 143-147. IB Tauris, London

2. Fuchs M, Höpken W, Lexhagen M (2014) Big data analytics for knowledge generation in tourism destinations-a case from Sweden. J Destin Mark Manag 3(4):198-209

3. Höpken W, Fuchs M, Keil D, Lexhagen M (2015) Business intelligence for cross-process knowledge extraction at tourism destinations. Inf Technol Tour 15(2):101-130. https://doi. org/10.1007/s40558-015-0023-2

4. Olszak CM, Ziemba E (2007) Approach to building and implementing business intelligence systems. Interdiscip J Inf Knowl Manag 2(1):135-148

5. Femenia-Serra F, Ivars-Baidal JA (2021) Do smart tourism destinations really work? The case of benidorm. Asia Pac J Tour Res 26(4):365-384

6. Gerrikagoitia JK, Rebón F, Alzua-Sorzabal A (2015) New trends of Intelligent E-Marketing based on Web Mining for e-shops. Procedia Soc Behav Sci 175:75-83

7. Shollo A, Galliers RD (2016) Towards an understanding of the role of business intelligence systems in organisational knowing. Inf Syst J 26(4):339-367 
8. Watson HJ, Wixom B (2007) Enterprise agility and mature BI capabilities. Bus Intell J 12 (3):4-6

9. Fuchs M, Abadzhiev A, Svensson B, Höpken W, Lexhagen M (2013) A knowledge destination framework for tourism sustainability: a business intelligence application from Sweden. Tour Int Interdiscip J 61(2):121-148

10. Alzua-Sorzabal A, Zurutuza M, Rebón F, Gerrikagoitia JK (2015) Obtaining the efficiency of tourism destination website based on data envelopment analysis. Procedia Soc Behav Sci 175:58-65

11. Braun V, Clarke V (2006) Using thematic analysis in psychology. Qual Res Psychol 3 (2):77-101

12. Gebauer J, Schober F (2006) Information system flexibility and the cost efficiency of business processes. J Assoc Inf Syst 7(3):122-145

13. Lonnqvist A, Pirttimaki V (2006) The measurement of business intelligence. Bus Intell 23 (1):32-40

14. Isik O, Jones MC, Sidorova A (2011) Business intelligence (BI) success and the role of BI capabilities. Intell Syst Account Finance Manag 18(4):161-176

Open Access This chapter is licensed under the terms of the Creative Commons Attribution 4.0 International License (http://creativecommons.org/licenses/by/4.0/), which permits use, sharing, adaptation, distribution and reproduction in any medium or format, as long as you give appropriate credit to the original author(s) and the source, provide a link to the Creative Commons license and indicate if changes were made.

The images or other third party material in this chapter are included in the chapter's Creative Commons license, unless indicated otherwise in a credit line to the material. If material is not included in the chapter's Creative Commons license and your intended use is not permitted by statutory regulation or exceeds the permitted use, you will need to obtain permission directly from the copyright holder. 